\title{
STRUCTURE OF PLANTAGONINE AND INDICAINE
}

A. Abdusamatov, M. R. Yagudaev, and S. Yu. Yunusov

Khimiya Prirodnykh Soedinenii, Vol. 4, No. 4, p. 265, 1968

The isolation and the determination of the structure of plantagonine (II) and indicaine (III) have been reported previously [1]. An analysis of the NMR spectrum of the methyl ether of plantagonine (I) (spectrum obtained on a JNM$4 \mathrm{H}-100 / 100 \mathrm{Mz}$ instrument in deuterochloroform) shows that in the weak-field region it exhibits only two one-proton singlets at $r 1.12$ and $1.56 \mathrm{ppm}$, corresponding to two hydrogen atoms located in the $\alpha$ - and $\alpha^{\prime}$-positions with respect to the nitrogen atom of a pyridine ring. The nonequivalence of these protons can be explained by the influence on them of the carbonyl group of COOR present in the $\beta$-position to the nitrogen atom of the ring. The absence of other signals in this region shows that the other three positions of the pyridine ring of (I) are substituted. The three-proton doublet at $\tau$ $8.74 \mathrm{ppm}, J=7.0 \mathrm{~Hz}$, relates to the protons $a$ of the methyl group of the cyclopentene ring [2]. The signal of the methine proton $b$ conjugated with a heterocyclic nucleus is displaced in the direction of weak fields and is superposed on the signal of the two protons ef the $\mathrm{CH}_{2}$-group, as a result of which the spectrum has a three-proton multiplet at $\tau 6.88$ ppm. The two one-proton multiplets at $\tau 7.71$ and $8.43 \mathrm{ppm}$ evidently relate to the two nonequivalent $\mathrm{CH}_{2}-\mathrm{group}$ protons $\mathrm{c}$ and $d$, one of which is in the axial orientation so that its signal is displaced in the strong field direction. The three protons of the methyl group of an ester give a narrow singlet at $\tau 6.16 \mathrm{ppm}$.


$$
\begin{aligned}
& \text { I } \mathrm{R}=-\mathrm{COOCH}_{3} \\
& \text { II } \mathrm{R}=-\mathrm{COOH} \\
& \text { III } \mathrm{R}=-\mathrm{C}_{-1}^{=0}
\end{aligned}
$$
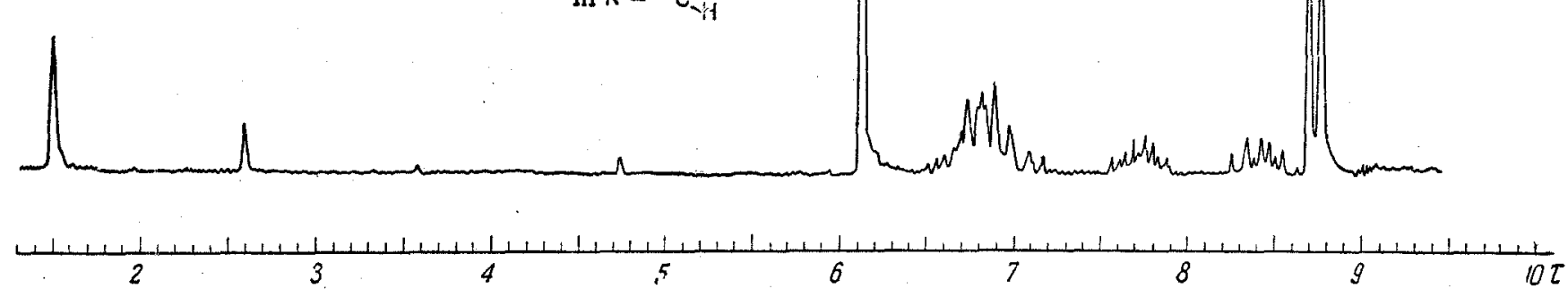

When plantagonine was oxidized with potassium permanganate in an alkaline medium, 12 oxygen atoms were consumed and we obtained an acid with $\mathrm{mp} 262-264^{\circ} \mathrm{C}$ (decomp). A mixture of the latter with 3,4,5-pyridinetricarboxylic acid, obtained by the oxidation of gentianamine [3] showed no depression of the melting point. The IR spectra of the two acids were also identical.

The information given shows that plantagonine has the structure (II) and indicaine (III) (figure).

\section{REFERENCES}

1. K. L. Lutfullin, P. Kh. Yuldashev, and S. Yu. Yunusov, KhPS [Chemistry of Natural Compounds], 1, 365, 1965.

2. Y. Hammouda and I. Le Men, Bull. Soc. Chem. France, 12, 2901, 1963.

3. A. S. Samatov, S. T. Akramov, and S. Yu. Yunusov, KhPS [Chemistry of Natural Compounds], 3, $182,1967$. 